\title{
Effect of L-carnitine enrichment on the rotifer and influences on clownfish larvae
}

\author{
S. Ghosh ${ }^{1,2^{*}}$, T.T. Ajith Kumar ${ }^{1}$ and N.C. Sahu ${ }^{22}$
}

\begin{abstract}
Enrichment has shown considerable influence on the population growth, reproduction and individual growth of rotifer (Brachionus plicatilis Müller, 1786) and its utility on the clownfish larvae (Amphiprion ocellaris Cuvier 1830). Using the culture medium of microalgae (Nannochloropsis salina D.J. Hibberd 1981) as the control, rotifers were enriched by dissolving in S-presso (for short term enrichment) or L-carnitine supplements. The study was conducted in three replicates for five and 10 days of batch culture. On day-4, the population density of rotifers exposed to 1,10 and $100 \mathrm{mg} \mathrm{I}^{-1} \mathrm{~L}$-carnitine was significantly increased $(p<0.001)$ by 43,39 and $54 \%$, respectively, compared to the control. The population density in these three treatments also increased on day-2, day-3 and day-5 compared to the $1000 \mathrm{mg} \mathrm{L}^{-1}$ treatment $(p<0.05)$ and control $(p<0.05)$. The body length $(p<0.001)$ and width $(p<0.05)$ were significantly reduced in the $1000 \mathrm{mgL}^{-1}$ treatment compared to the control. The mean values of total unsaturated fatty acids (PUFA's, HUFA's and $n-3$ fatty acids) and the ratio of $n-3 / n-6, D H A / E P A, E P A / A A$ were significantly higher $(p<0.05)$ in the rotifers enriched with L-carnitine compared to S-presso and algae. Larvae fed using rotifer enriched with Lcarnitine gained the maximum growth $(65.7 \pm 1 \mathrm{mg})$, followed by those enriched with S-presso (42.2 $\pm 0 \mathrm{mg})$. In L-carnitine treatment, metamorphosis took only 9 days, followed by the control. In L-carnitine and S-presso units, the clownfish larvae took only three days for the first pigmentation compared to four days in N. salina (control) and 10 days with S-presso. Rotifers enriched with L-carnitine showed the highest survival rate $(70 \%)$ of the clownfish followed by the control (68\%) and S-presso (52\%). The results suggested that L-carnitine could be a positive factor to enhance the rotifer production and also its utilization in clownfish larval culture.
\end{abstract}

Keywords: L-carnitine, rotifer, Amphiprion ocellaris, enrichment, growth, survival

\section{Introduction}

Rotifers are microscopic metazoans and are the most important live food of fish larvae especially during the early period of exogenous feeding (Hagiwara et al., 2001). The nutrients available in the rotifer (Brachionus plicatilis Müller, 1786) include highly unsaturated fatty acids (mainly 20:5n-3 and 22:6n-3) that are essential for survival of marine fish larvae (Zhang et al., 2002). Watanabe et al. (1983) have shown that high quality feed i.e. a mixture of algae and other enrichment, facilitate the transfer of essential fatty acids and other dietary components from algae via the

\footnotetext{
1 Centre of Advanced Study in Marine Biology, Faculty of Marine Sciences, Annamalai University, Parangipettai, Tamil Nadu, India

2 "Sasya Shyamala" Krishi Vigyan Kendra, Indian Council of Agricultural Research (ICAR), School of Agriculture and Rural Development, Ramakrishna Mission Vivekananda University, Kolkata, India

* Corresponding author: swagotor@gmail.com
} 
rotifers to marine fish larvae. Two types of products are normally used for enrichment viz. L-carnitine and a commercially available liquid enrichment 'S-presso'. Many researchers have used L-carnitine as supplements for vitamin-like nutrients to foster the oxidation of long-chain fatty acids by the mitochondria and stimulate protein sparing action by increasing energy derived from lipids (Emaus and Bieber, 1983). Despite conflicting results, most of the studies have demonstrated that administration of L-carnitine has ameliorated fish growth performance, stress tolerance and reproduction, while reducing the body fat content and stimulating lipid metabolism (Zhang et al., 2002).

Some methods to enhance rotifer production and growth through environmental manipulations and chemical treatments have been already investigated targeting good production for larval feed demand (Dhert et al., 2001; Hagiwara et al., 2001). Nutritional manipulations of enhancement with vitamins such as $B_{12}, C, A, D$ and $E$ and $n-3$ highly unsaturated fatty acids - HUFA (eicosapentaenoic acid - EPA and docosahexaenoic acid - DHA) have been developed as methods for rotifer mass culture (Yoshimatsu et al., 1997). Approaches of manipulating the biological characteristics in rotifers with chemical treatments have achieved effective results (Yoshimatsu et al., 1997) and have revealed that enrichments play a metabolic role on rotifers as it does on the fish. The L-carnitine administration could enhance growth and reproduction of rotifers by stimulating lipid catabolism. Hence, the present study was aimed to investigate the effects of administrating enrichments on the population growth, reproduction and body size of a selected marine rotifer under individual and batch culture conditions. The study also made a comparison between microalgae and commercially available enrichments through clinical application on the larvae of false clownfish Amphiprion ocellaris (Cuvier 1830).

\section{Materials and Methods}

\section{Carnitine supplementation and S-Presso enrichment Individual culture experiment}

The commercially available L-carnitine (inner salt, $98 \%$ ) enrichment and S-presso were used for this study (Sigma Co. Inc.). The L-carnitine was selected for the study as it met the requirement of HUFA or DHA/EPA and EPA/AA ratio for fatty acids. They were standardized with the concentrations of $0,0.001,0.01,0.1,1,10,100$ and 1000 $\mathrm{mg}$ with $\mathrm{N}$. salina culture medium at $7 \times 10^{6} \mathrm{cells} \mathrm{ml}^{-1}$ in glass test tubes (Borosil, India). The S-type marine rotifer B. plicatilis was used for the experiment. In order to ensure that the rotifers are of same age, eggs were collected by shaking the eggbearing females in a screw-capped bottle. The neonatal rotifers developed to one egg-bearing female and they were pipetted individually into separate test tubes containing $5 \mathrm{ml}$ of the $\mathrm{N}$. salina with different enrichments at temperature $\left(28^{\circ} \mathrm{C}\right)$. The initial rotifer density was 1 individual $/ \mathrm{ml}$. The culture medium enriched with different levels of enrichment was enhanced with $N$. salina at $7 \times 10^{6}$ cells $\mathrm{ml}^{-1}$, renewed at every $48 \mathrm{hr}$ and kept at the same temperature. 
The experiment in triplicates was maintained with filtered seawater at $30 \pm 2{ }^{\circ} \mathrm{C}$, $26 \pm 2 \%$ salinity and $12 \mathrm{hr} / 12 \mathrm{hr}$ day/night period. The specific growth rate was calculated according to Rico-Martinez and Dodson (1992). The initial density was 250 individual/ml and it was monitored daily by counting the number of rotifers in $3 \mathrm{ml} / \mathrm{L}$ samples at each treatment. The egg ratio was calculated using the Equation 1 as described by (Zhang et al., 2002)

$$
\text { Egg ratio }=\text { amictic egg numbers/rotifers } \quad \text { (Equation 1) }
$$

\section{Body size determination}

At the last day of the culture trial, the Lorica length and width were measured using a microscope (Leica model) at $100 \times$ magnification with computed length analysis software to determine the body size of a rotifer. One-egg carrying rotifers were randomly measured ( $n=120$ per treatment). The rotifers were fixed with $6.5 \% \mathrm{HCl}$ as described by Fu et al. (1991), for easy measurement without a significant shrinkage.

\section{Storage and analysis}

After bio-encapsulation, these enriched rotifers were collected, washed properly and stored in vials under $-80^{\circ} \mathrm{C}$. Total lipids were extracted from the enriched rotifers using Bligh and Dyer method (1959) at A to Z Pharmaceuticals Laboratory in Chennai, India, and the fatty acid analysis were done using Gas Chromatography (Chrompak (P- $9001 \mathrm{GC})$.

\section{Larval feeding}

The capacity of each larval rearing tank was $100 \mathrm{I}$, well-aerated under $26-32{ }^{\circ} \mathrm{C}$ temperature, $\mathrm{pH}, 8.0-8.2$, salinity $24-28 \%$ and ammonia $<0.01 \mathrm{ppm}$. The rotifer density was maintained at $8-10$ individuals $/ \mathrm{ml}$. Sixty larvae were measured to the nearest 0.05-0.15 mg individually and introduced to each larval-rearing tank. Every morning, tanks were clearly checked and dead larvae were counted and removed along with the debris settled in the bottom adopting a siphoned method. Approximately $20 \%$ water exchange was maintained at the experimental tanks to avoid rotifers settlement at the bottom. To keep the rotifer population at 8-10 individuals $/ \mathrm{ml}$, the enriched feed was supplied on 8-10 am and 4-6 pm. The experiment was continued for a period of 15 days and the final wet weight was obtained. Throughout the experimental period, the records on rotifer growth in terms of weight $(\mathrm{mg}), \%$ survival and number of days taken for pigmentation and metamorphosis under different treatments were obtained.

\section{Analysis of growth and culture evaluation}

Larval dry weight was calculated by weighing larvae at the size of $3.5 \mathrm{~mm}$ on prewashed and pre-weighed fibreglass filters following the method proposed by Zhang et al. (2002). The specific growth rate was calculated from the slope of the linear regression of log-transformed dry weight against age (Albentosa et al., 1997). The 
final biomass was calculated with the dry weight and the larval density was obtained at the end as described by (Cahu et al., 1998). The dissolved oxygen level (mg/l) and $\mathrm{pH}$ were measured daily. The ammonia and nitrite level at each tank were analyzed as described by Albentosa et al. (1997).

\section{Statistical analysis}

The values on population density were transformed to a logarithmic scale and the egg ratio to the square root for statistical analysis. One-way ANOVA was conducted and the significant differences among treatments on each day by Duncan's multiple range test (DMRT) at $\mathrm{p}=0.05$ (Zar, 1999). All statistical analyses were performed using SPSS 20.0 statistical software package and Figures were made using Origin 6.1 software.

\section{Results}

\section{Effects on growth population}

The rotifers enriched with $1000 \mathrm{mgl}^{-1} \mathrm{~L}$-carnitine showed $100 \%$ mortality at the end of $10^{\text {th }}$ day of culture. The population density of other 6 groups (treated with $0-10 \mathrm{mgl}^{-1}$ $\mathrm{L}$-carnitine) except for rotifers enriched with higher level of 100 and $1000 \mathrm{mg} \mathrm{l}^{-1} \mathrm{~L}$ carnitine, showed a clear population increase after 5 and 10 days of culture (Figure 1). However, the 100 and $1000 \mathrm{mgl}^{-1}$ treatments showed a decreasing trend in population density. Compared to the first 5 days, the specific growth rate of rotifers in all treatments decreased during the last 5 days of the experiment.

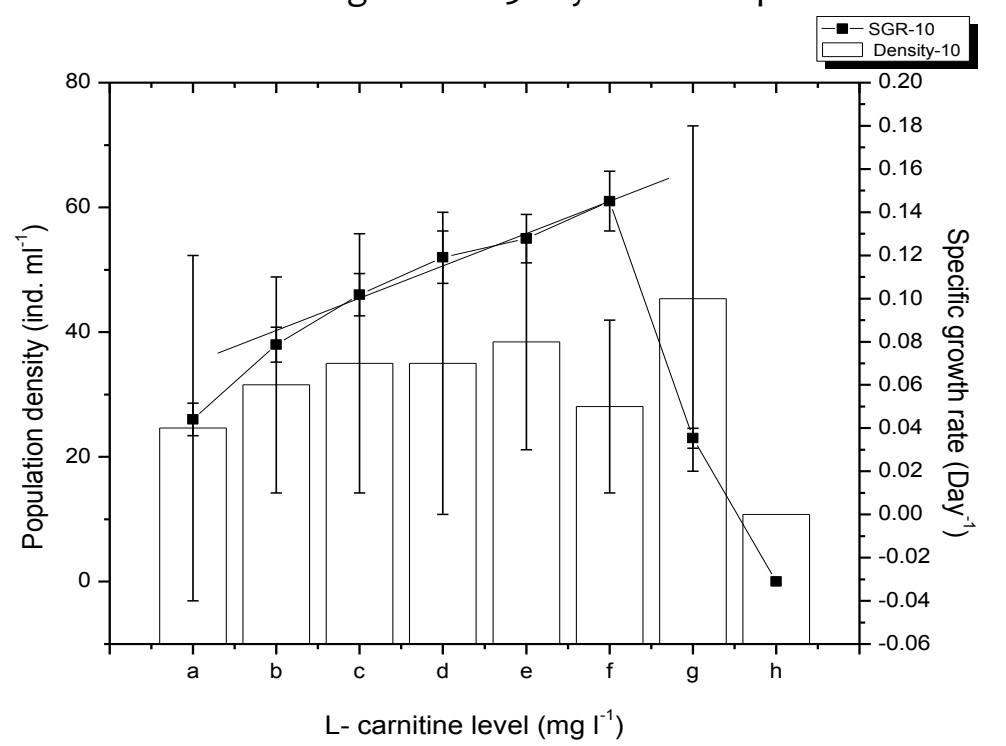

Figure 1. Population density (individuals $\mathrm{ml}^{-1}$ ) and specific growth rate $\left(\right.$ day ${ }^{-1}$ ) of B. plicatilis enriched with eight levels of L-carnitine ( $\mathrm{mg} \mathrm{I}^{-1}$ after 10 days) individual culture. Vertical lines indicate the standard error. Note: concentrations of $L$-carnitine $\left(\mathrm{mg} \mathrm{l}^{-1}\right)$ in $a=0, b=0.001, c=0.01$, $d=0.1, e=1.0, f=10, g=100$, and $h=1000$. 
The population densities between treatments were significantly different at different culture trials $(p<0.05)$. On the day- 4 , the population density of the rotifers exposed to 1,10 and $100 \mathrm{mgl}^{-1} \mathrm{~L}$-carnitine increased by 43,39 and $54 \%$, respectively, $(p<0.001)$ compared to the control. The same treatments also showed an increase in population density of rotifers in day-2, day-3 and day- 5 compared to treatment with $1000 \mathrm{mg} \mathrm{l}^{-1} \mathrm{~L}$-carnitine and the control $(\mathrm{p}<0.05)$. From day-2 to day-5 of the experiment, the rotifers enriched with $1000 \mathrm{mg} \mathrm{I}^{-1} \mathrm{~L}$-carnitine showed $33-35 \%$ decrease in population density $(p<0.01)$ compared to the untreated control (Figure 2).

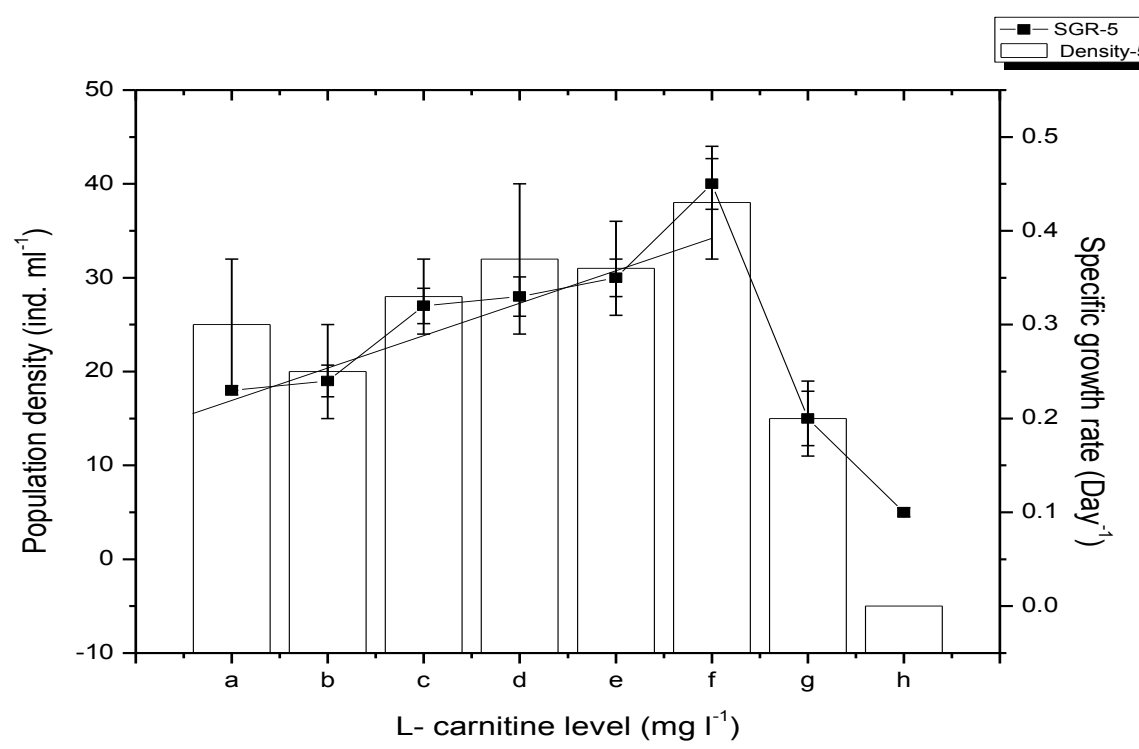

Figure 2. Population density (ind. $\mathrm{ml}^{-1}$ ) and specific growth rate $\left(\right.$ day $\left.^{-1}\right)$ of $B$. plicatilis enriched with eight levels of L-carnitine ( $\mathrm{mg} \mathrm{l}^{-1}$ after 5 days) individual culture. Vertical lines indicate the standard error. Note: concentrations of L-carnitine $\left(\mathrm{mg} \mathrm{l}^{-1}\right)$ in $a=0, b=0.001, c=0.01, d=0.1$, $e=1.0, f=10, g=100$, and $h=1000$.

\section{Effects on the egg ratio}

Figure 3 illustrates the egg ratio variation in B. plicatilis enriched with five levels of Lcarnitine during five days of batch culture. The 1 and $10 \mathrm{mgl}^{-1}$ treatments showed a significantly lower egg ratio on day-4 $(p<0.01)$ compared to the control. The egg ratio of all groups decreased after 24 hrs followed by an increase in L-carnitine enriching levels.

\section{Effects on the body size}

The $1000 \mathrm{mgl}^{-1} \mathrm{~L}$-carnitine treatment significantly increased $(p<0.001)$ the body length of rotifers with a marginal reduction in the width $(p<0.05)$, compared to the control. In the other three treatments (1,10 and $100 \mathrm{mg} \mathrm{I}^{-1} \mathrm{~L}$-carnitine), a larger body size was recorded (Figure 4). The results showed that in $1 \mathrm{mgl}^{-1} \mathrm{~L}$-carnitine treatment, body length of rotifers increased significantly $(p<0.05)$ but not their width $(p>0.05)$. However, at $100 \mathrm{mg} \mathrm{I}^{-1}$ treatment resulted in a significantly larger body width 
$(p<0.05)$ and marginally higher body length. There were no significant differences in the changes in the body size in $10 \mathrm{mg} \mathrm{I}^{-1} \mathrm{~L}$-carnitine treatment and the control $(p>0.05)$.

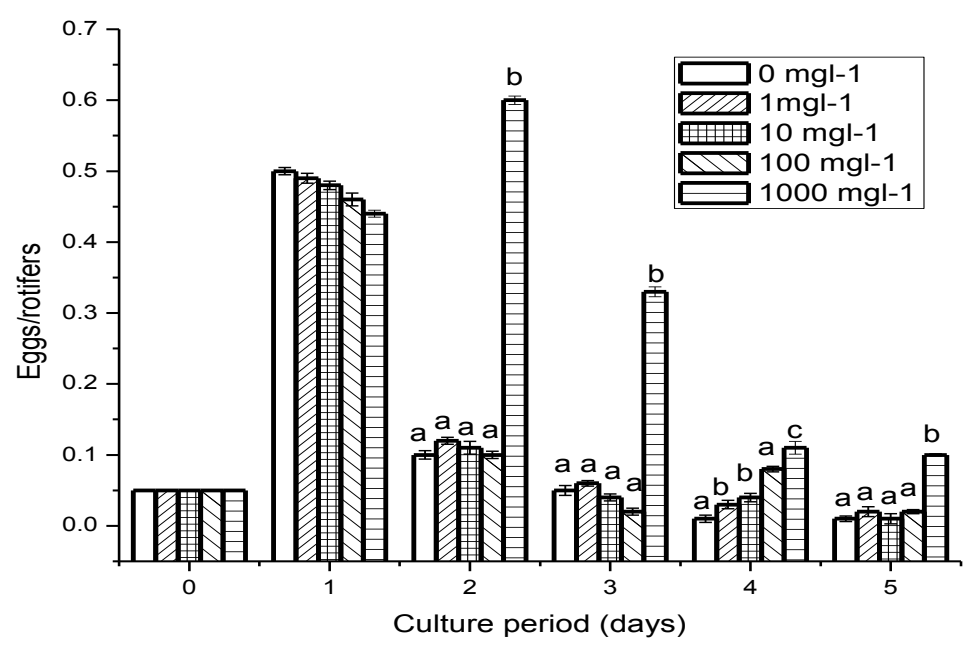

Figure 3. Egg ratio of B. plicatilis enriched with five levels of L-carnitine $(0,1,10,100$ and 1000 $\mathrm{mgl}^{-1}$ ) during 5 days batch culture. In each day, bars represented by the same letter are not significantly different by the DMRT at $\mathrm{p}=0.05$.

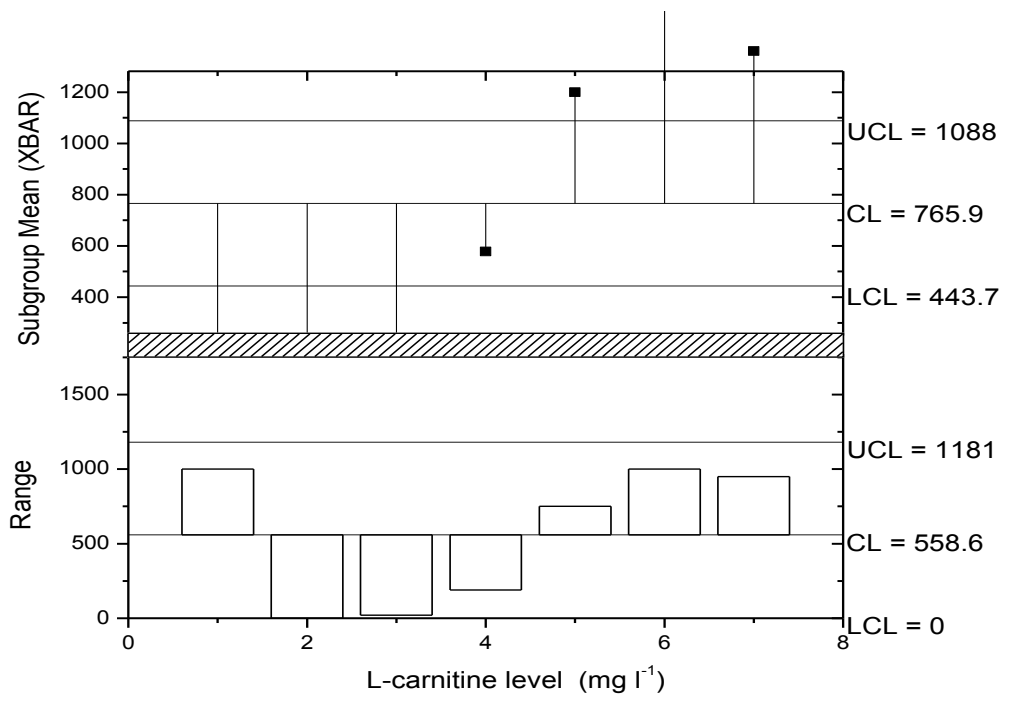

Figure 4. Body size increase or decrease (\%) compared to the control in B. plicatilis enriched with different concentrations of $L$-carnitine (level $1=0$, level $2=1$, level $3=10$, level $4=100$ and level $5=1000 \mathrm{mgl}^{-1}$ ) after 5 days batch culture. $U C L=$ upper confidence level, $C L=$ confidence level; $\mathrm{LCL}=$ lower confidence level 


\section{Fatty acid analysis of enriched encapsulated rotifers}

The L-carnitine enriched rotifer was found to be superior to other diets in terms of fatty acid content, with the ration of 1:7:0.5 (Table 1). The ratio for other diets namely, $N$. salina-enriched rotifers $0.4: 8.4: 0.2$ and S-presso-enriched rotifers $0.2: 7.0: 0.05$.

Table 1. Fatty acid composition (area \%) of total lipids of rotifers nutritionally enriched with different enrichment diets

\begin{tabular}{|c|c|c|c|}
\hline Fatty acids & N. salina & L-carnitine & S-presso \\
\hline $8: 0$ & $0.49 \pm 0.025$ & $0.69 \pm 0.06$ & $0.09 \pm 0.015$ \\
\hline 10: 0 & 0 & 0 & 0 \\
\hline 12: 0 & $0.31 \pm 0.03$ & $0.45 \pm 0.03$ & $0.36 \pm 0.06$ \\
\hline 14: 0 & $6.45 \pm 0.35$ & $032 \pm 0.04$ & $4.54 \pm 0.16$ \\
\hline 16: 0 & $36.61 \pm 1.19$ & $4.62 \pm 0.49$ & $6.25 \pm 0.36$ \\
\hline $16: 1 \mathrm{n} 7$ & $17.19 \pm 0.99$ & $28.93 \pm 0.58$ & $32.19 \pm 0.63$ \\
\hline 18: 0 & $0.56 \pm 0.04$ & $16.01 \pm 0.81$ & $4.09 \pm 002$ \\
\hline 18: 1ng & $9.02 \pm 0.28$ & $28.96 \pm 0.08$ & $7.26 \pm 0.025$ \\
\hline 18: $2 n-6$ & $7.13 \pm 0.37$ & $8.62 \pm 0.29$ & $8.17 \pm 0.12$ \\
\hline 18: $3 n-3$ & 0 & $21.03 \pm 0.22$ & $17.55 \pm 235$ \\
\hline 20: 0 & 0 & $7.62 \pm 0.13$ & $0.32 \pm 0.035$ \\
\hline $20: 1$ & 0 & $0.49+0.04$ & 0 \\
\hline $20: 4 n-6$ & $0.41 \pm 0.025$ & $29.12 \pm 0.17$ & $13.93 \pm 0.725$ \\
\hline $20: 5 n-3$ & $16.69 \pm 0.385$ & $2.09 \pm 0.06$ & 0 \\
\hline $22: 6 n-3$ & $0.79 \pm 0.03$ & $29.12 \pm 0.17$ & 0 \\
\hline Unidentified & $4.08 \pm 0.26$ & $7.71 \pm 0.06$ & 0 \\
\hline$\Sigma$ saturated & $44.43 \pm 0.79$ & $46.22 \pm 1.29$ & $3282 \pm 0.665$ \\
\hline$\Sigma$ unsaturated & $51.22 \pm 078$ & $76.78 \pm 0.47$ & $53.1 \pm 0.065$ \\
\hline$\Sigma$ HUFA & $17.48 \pm 0.42$ & $33.2 \pm 0.1$ & $14.31 \pm 0.695$ \\
\hline$\Sigma \mathrm{n}-3$ fatty acids & $17.48 \pm 0.42$ & $54.23 \pm 0.12$ & $17.55 \pm 2.35$ \\
\hline$\Sigma \mathrm{n}-6$ fatty acids & $7.54 \pm 0.35$ & $10.71 \pm 0.35$ & $8.17 \pm 0.12$ \\
\hline$\Sigma$ MUFA & $26.21 \pm 0.71$ & $11.84 \pm 0.01$ & $43.47 \pm 0.13$ \\
\hline$\Sigma$ PUFA & $7.54 \pm 0.35$ & $31.74 \pm 0.57$ & $9.63 \pm 0.065$ \\
\hline$n-3 / n-6$ & $2.33 \pm 0.16$ & $50.63 \pm 0.17$ & $0.18 \pm 0.026$ \\
\hline DHA/EPA & $0.05 \pm 0.007$ & $0.027 \pm 0.004$ & $0.14 \pm 0.016$ \\
\hline EPA/AA & $41.19 \pm 15.4$ & $11.60 \pm 3.625$ & $13.93 \pm 3.09$ \\
\hline
\end{tabular}

Values are means for two replicate samples \pm standard error; HUFA=n-3 highly unsaturated fatty acids; EPA=eicosapentaenoic acid; DHA=docosahexaenoic acid; MUFA=

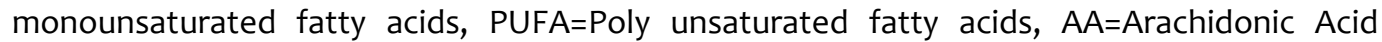
DHA:EPA:AA ratios for N. salina-fed rotifers 0.4:8.4:0.2, S-presso-fed rotifers 0.2:7.0:0.05, Lcarnitine-fed rotifers 1:7:0.5.

Table 2 shows the fatty acid profile of rotifers enriched with L-carnitine, S-presso and $N$. salina. The enrichments effects are statistically significant $(p<0.01)$. The mean values of total unsaturated fatty acids, PUFA's, HUFA's and $n-3$ fatty acids and their ratios such as $n-3 / n-6, D H A / E P A, E P A / A A$ were significantly higher $(p<0.05)$ in the 
rotifers enriched with L-carnitine compared with other diets. An exceptionally high PUFA content was recorded in rotifers enriched with S-presso (46.55) and the ratio of EPA/AA was high in rotifers enriched with L-carnitine (118.321). The high PUFA content in rotifers enriched with L-carnitine was mainly due to the contribution of 18:3n-3 to the total PUFA content. The total unsaturated fatty acid, n-3 fatty acids, HUFA, DHA, EPA, AA levels and their ratio are show in Table 3.

Table 2. ANOVA for selected fatty acids of rotifers enriched with N. salina, L-carnitine and Spresso treatments

\begin{tabular}{cccccc}
\hline $\begin{array}{c}\text { Source of } \\
\text { variation }\end{array}$ & $\begin{array}{c}\text { Sum of } \\
\text { squares }\end{array}$ & df & $\begin{array}{c}\text { Mean } \\
\text { square }\end{array}$ & $F$ & Significance \\
\hline UFA & $1,14,388$ & 4 & 286.09 & 39.4 & 0.005 \\
Error & 30,667 & 3 & 6.88 & & \\
HUFA & $1,53,388$ & 4 & 367.98 & $1,450.5$ & 0.005 \\
Error & 1,543 & 3 & 0.24 & & \\
n-3 & 3,087 & 4 & 775.86 & 309.4 & 0.005 \\
Error & 21.56 & 3 & 2.46 & & \\
PUFA & 2579 & 4 & 642.54 & 112.5 & 0.005 \\
Error & 12.56 & 3 & 5.53 & & \\
n-3/n-6 & 32,755 & 4 & 7.89 & 339.5 & 0.005 \\
Error & 27.73 & 3 & 0.09 & & \\
DHA/EPA & .0321 & 4 & 0.01 & 160.3 & 0.005 \\
Error & 0 & 3 & 0 & & \\
EPA/AA & 20,867 & 4 & $4,654.5$ & 64.4 & 0.005 \\
Error & 367.9 & 3 & 75.67 & & \\
\hline
\end{tabular}

UFA=unsaturated fatty acids, HUFA=highly unsaturated fatty acids, PUFA=polyunsaturated fatty acids, $\mathrm{DHA}=$ docosahexaenoic acid, $\mathrm{EPA}=$ eicosapentaenoic acid, $\mathrm{AA}=$ arachidonic acid

Table 3. DMRT grouping for total fatty acid fraction of rotifers enriched with various diets

\begin{tabular}{lllllll}
\hline \multirow{2}{*}{ Enrichments } & \multicolumn{6}{c}{ Values } \\
\cline { 2 - 6 } & $\Sigma$ unsaturated & HUFA & PUFA & n-3 & DHA/EPA & EPA/AA \\
\hline N. salina & $51.22^{\mathrm{b}}$ & $17.48^{\mathrm{b}}$ & $7.54^{\mathrm{c}}$ & $17.36^{\mathrm{b}}$ & $0.05^{\mathrm{b}}$ & $41.3^{\mathrm{b}}$ \\
L-carnitine $^{\mathrm{a}}$ & $76.31^{\mathrm{a}}$ & $33.31^{\mathrm{a}}$ & $31.76^{\mathrm{a}}$ & $54.11^{\mathrm{a}}$ & $0.15^{\mathrm{a}}$ & $25.23^{\mathrm{a}}$ \\
S-presso & $53.03^{\mathrm{b}}$ & $22.03^{\mathrm{b}}$ & $9.03^{\mathrm{c}}$ & $3.03^{\mathrm{c}}$ & $0.2^{\mathrm{a}}$ & $14.2^{\mathrm{c}}$ \\
\hline HUFA=highly & unsaturated & fatty & acids, & PUFA=polyunsaturated fatty & acids, \\
DHA=docosahexaenoic acid, EPA=eicosapentaenoic acid, AA=arachidonic acid
\end{tabular}

\section{Larval rearing of $A$. ocellaris}

The initial wet weight of the newly hatched $A$. ocellaris larvae was $0.75 \pm 0.2 \mathrm{mg}$ (Figure 5). The larval growth after 15 days varied with different treatments. The rotifers enriched with L-carnitine helped larvae reaching the maximum growth 
$65.67 \pm 1 \mathrm{mg}$, followed by those enriched with S-presso (42.2 $\pm .04 \mathrm{mg})$. The rotifers enriched with $N$. salina resulted in a larval body eight of $42.2 \pm 0.04 \mathrm{mg}$.

The number of days taken for the first pigmentation of clownfish larvae, i.e. from translucent colour to dull black colour, differed among treatment. In the L-carnitine and S-presso treatments, the larvae took only three days for the first pigmentation, whereas four days were taken in the N. salina treatment (Table 4). The number of days taken by the clownfish larvae to show the initial signs on metamorphosis changed with different feeds (Table 4), i.e. nine days in L-carnitine treatment followed by 10 days in N. salina; and 10 days in S-presso.

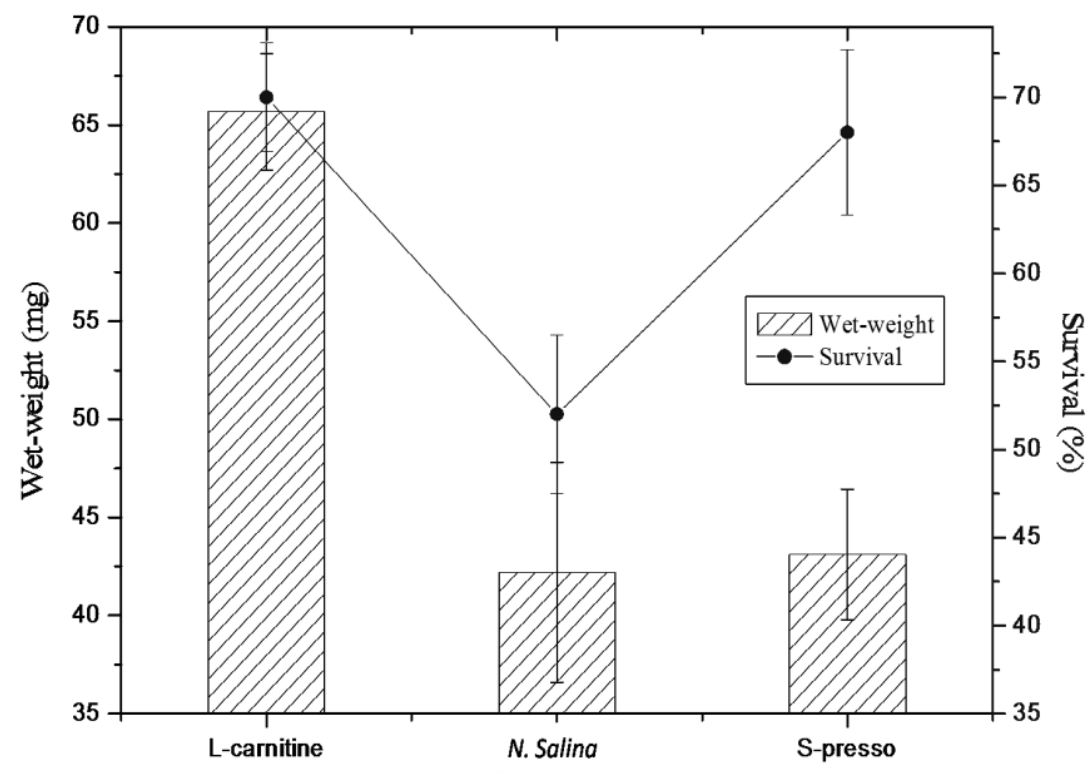

Enriched rotifers

Figure 5. Weight (mg) and survival (\%) of A. ocellaris larvae enriched with different diets.

Table 4. Pigmentation, metamorphosis stages (days), Growth (mg) and survival (\%) of the A. ocellaris fed with rotifers enriched with various sources

\begin{tabular}{clcccc}
\hline $\begin{array}{l}\text { Experimental } \\
\text { duration } \\
\text { (DAH) }\end{array}$ & $\begin{array}{l}\text { Enrichmen } \\
\text { t media }\end{array}$ & $\begin{array}{l}\text { Wet weight } \\
\text { gained }(\mathrm{mg})\end{array}$ & $\begin{array}{c}\text { Pigmentatio } \\
\mathrm{n}(\mathrm{DAH})\end{array}$ & $\begin{array}{c}\text { Metamorphosi } \\
\mathrm{s}(\mathrm{DAH})\end{array}$ & $\begin{array}{c}\text { Survival } \\
\text { rate (\%) }\end{array}$ \\
\hline 15 & L-carnitine & $65.67 \pm 1$ & 3 & 9 & 70 \\
15 & S-presso & $42.2 \pm 0.04$ & 4 & 10 & 52 \\
15 & N. salina & $43.12 \pm 1$ & 3 & 10 & 68 \\
\hline
\end{tabular}

DAH=days after hatching

The survival percentage of clownfish larvae (Figure 5) was the highest (70\%) in Lcarnitine treatment followed by the N. salina (68\%), S-presso (52\%). Mortality of larvae in N. salina treatment was noticed during day-2 and day-3. Mortality during 
day-7 and day- 8 were less than $5 \%$ during metamorphosis. In N. salina treatment, less than $30 \%$ mortality was recorded from day-4 to day- 10 .

Larvae fed at S-presso attained the maximum growth $56.92 \pm 0.2 \mathrm{mg}$, followed by L-carnitine (48.74 $\pm 1 \mathrm{mg}$ ), and those fed with an algae-enriched rotifers recorded the maximum growth of $39.41 \pm 3 \mathrm{mg}$. Observations made on the number of days taken for first pigmentation indicates that L-carnitine and S-presso take only 3-4 days followed by N. salina (4-5 days).

\section{Discussion}

The L-carnitine supplement (1500 $\mathrm{mgl}^{-1}$ ) has shown a significant response on the metabolism of treated European sea bass fry (Santulli et al., 1990). The present study showed similar results demonstrating that supplemented L-carnitine in culture medium has resulted in significant responses in reproduction and individual growth of enriched rotifers. The mechanical and chemical receptors of rotifers are sensitive to environmental stimulation and are in direct contact with external medium (Clement et al., 1983). Thus, it is possible that rotifers exposed to a medium enriched with L-carnitine are affected directly. This study was not conducted in an axenic condition and hence, other associated microorganisms that may interact in the trophic relationship were also exposed to supplemented L-carnitine in culture medium (Lubzens et al., 1985).

The supplemented of L-carnitine to the culture may change the normal interaction between the microenvironment and rotifers, which could be either detrimental or beneficial. In the present study, 38-50\% improvement in population density was detected in rotifers treated with 1-100 $\mathrm{mgl}^{-1} \mathrm{~L}$-carnitine. Rotifers exhaust endogenous lipid through reproduction (anabolism) and respiration (Olsen et al., 1993). In the individual culture trial, rotifers enriched with $1000 \mathrm{mg} \mathrm{l}^{-1}$ of L-carnitine showed $100 \%$ mortality on day-10. Oie and Olsen (1997) reported that higher food ration resulted in higher growth rate, and then rotifers respond by a higher egg ratio. Normally, high reproduction causes smaller size as more energy is allocated for reproduction over somatic growth (Duncan, 1989). As observed in this study, increased body size of clownfish larvae when fed with rotifers in the 1-100 $\mathrm{mg} \mathrm{l}^{-1} \mathrm{~L}$ carnitine treatment may be the response to the protein sparing action produced by exogenous L-carnitine stimulation. In this treatment, rotifer did not show a higher egg ration compared to the treatment with $1000 \mathrm{mg} \mathrm{l}^{-1} \mathrm{~L}$-carnitine however, they achieved a larger body size and improved population growth.

The nutritional quality of rotifers was improved by feeding them on algae or, on emulsified Pollock or cattle fish oil prior to their transfer into fish tanks (Watanabe et al., 1983). The relationship between the $n-3$ and $n-6$ fatty acid series, and more recently, the DHA/EPA, EPA/AA, and DHA: EPA:AA ratios seem to be indicators of the best survival and growth of marine fish larvae (Sargent et al., 1997). Selco, Super Selco and Topal emulsions (Artemia systems, Belgium) are also used for enrichment. The S-presso, one of the enrichment diets in the present study have a good source of 
HUFA's (32.2 \%) and total unsaturated fatty acids (76.78 \%) is also used as a short term enrichment. Results presented in Table 1 showed that L-carnitine DHA is higher than EPA and AA is present in higher levels. The subsequent slow increase of fish larval growth rate was due to an incorporation of $n-3$ fatty acids and sufficient period after enrichment to serve as a live feed for marine fish larvae (Olsen et al., 1993). The increase in n-3 HUFA levels of enriched rotifers fed on capelin oil or by low temperature crystallization separation for rotifer enrichment reached a maximum between 6 and 12 hrs of enrichment and did not change significantly thereafter (Kissil and Koven, 1990).

In the present study, rotifer fed with $N$. salina gave a very good fatty acid profile especially HUFA, and n-3 fatty acids, the n-3/n-6, DHA/EPA and EPA/AA ratios. In turbot (Scophthalmus maximus Linnaeus, 1758), the dietary deficiencies in AA have resulted in high mortality and obvious pathology (Bell et al., 1985), while Castell et al. (1994) reported a positive effect of AA on survival of turbot from levels ranging from $0.5-1.0 \%$. The total HUFA fraction in the enriched rotifers revealed that rotifers enriched with S-presso contained the highest percentage of HUFA fraction among the tested feed, where the major contribution is from the DHA and EPA fatty acids, which the marine fish is lacking (Sargent et al., 1997). The rotifers enriched with Spresso had more 20:4n-6, which has an essential function in producing eicosanoids, compared to N. Salina, however, showed lower level than in L-carnitine. Arachidonic acid is essential for certain marine fin fishes (Castell et al., 1994). The DHA:EPA:AA ratio, which is important for marine finfish larvae was promising in rotifers enriched with L-carnitine (1:7:0.5) followed by those enriched with $N$. salina (0.4:8.4:0.2). Except in oil-enriched rotifers, the DHA level is generally low but the EPA levels are high. In marine finfish larvae, the conversion of EPA to DHA is possible to meet the requirement of DHA. The results suggested a strong possibility of retro-conversion of DHA to EPA in rotifers, as the high content of DHA in S-presso was not reflected after enrichment of rotifers. After enriching with S-presso, rotifers should be handled with care as if not, it could result in rotifer releasing out or vomiting the enrichment taken in.

Clown fish larvae can be reared up to metamorphosis with enriched rotifers. Two main live feeds are used for marine fish seed production, rotifers and brine shrimp nauplii (Dhaneesh et al., 2012). The major source, n-3 HUFA for live organisms can also vary substantially (Sargent et al., 1997). Clownfish larvae can be weaned on to a formulated dry feed for seven days after hatch with no significant reduction in survival, although the optimum time for weaning on a dry formulated feed was between 15 and 20 days after hatch (Ajith Kumar and Balasubramanian, 2009).

The enrichment products, S-presso and micro alga $N$. salina, had EFA such as 20:5n-3, 22:6n-3 and PUFA such as 20An-6, vitamins such as $B_{12}, C$ and $A$ that could be utilized and easily incorporated into this feeding regime. The long-chain highly unsaturated fatty acids (HUFA's), particularly EPA and DHA, are important in the nutrition of young marine fish (Watanabe et al., 1983). The DHA and EPA arachidonic acid (AA, 20An-6) has also been recognized as essential for marine fish (Castell et al., 
1994). In the present study, a significant difference was observed in the growth and survival of clownfish larvae fed with DHA-enriched live food (high DHA/EPA ratio) i.e. S-presso, L-carnitine and N. salina. Baker et al. (1998) also noted a direct relationship between normal pigmentation and levels of DHA in the diet of summer flounder larvae, where the DHA/EPA ratio in the enriched live food was high. In the present study, however, pigmentation success was significantly higher in clownfish larvae fed with rotifers containing L- carnitine. The fatty acid profile of rotifers enriched with L-carnitine and S-presso showed higher levels of DHA compared to that of $\mathrm{N}$. salina. Recent research has shown that the n-6 HUFA, arachidonic acid (20An-6 or AA) was also important for growth, survival and stress resistance flounder (Baker et al., 1998). In milkfish (Chanos chanos Forsskal, 1775), the effects of DHA-enriched live food on growth may not be readily discussed over a short period but rather after extended rearing (Gapasin and Duray, 2001). The DHA must be present in the diet to maximize the survival of larvae of damselfish (Acanthochromis polyacanthus Bleeker, 1855; Southgate and Kavanagh, 1999). The AA was nutritionally more important in tropical species than in temperate species. Nannochloropsis salina contained relatively high levels ( $4.6 \%$ ) of AA (Thrush et al., 1993). In the present study, the rotifer enriched with L-carnitine and $N$. salina satisfied the $A A$ requirement of clownfish larvae. Sargent et al. (1997) stated that both the amount and proportions of DHA, EPA and AA are important in marine fish nutrition and suggested that the optimum ratio may vary with species but, would be in the range of 10:5:1 for DHA:EPA:AA. Free tyrosine and free phenylalanine have been reported to increase or to be maintained at constant levels around first feeding in European seabass (Dicentrarchus labrax Linnaeus, 1758; Ronnestad et al., 1998), Asian seabass (Lates calcarifer Bloch, 1790; Sivaloganathan et al., 1998), and Senegalese sole (Solea senegalensis Kaup, 1858; Parra et al., 1999).

\section{Conclusion}

Supplementation with L-carnitine can affect rotifers directly and indirectly. The rotifers enriched with L-Carnitine showed positive and significant responses to population growth, reproduction and individual growth under the optimum Lcarnitine concentration. The optimum concentration of supplemented L-carnitine in the culture medium is $1 \mathrm{mg} \mathrm{l}^{-1}$. Other biological and abiotic environments may be considered when the rotifer is enriched by L-carnitine in a normal culture medium. The rotifers enriched with L-carnitine as a feed may further influence the growth of clownfish larvae, in some aspects. The present study also revealed that commercial $\mathrm{L}$-carnitine and S-presso are promising as long- and short-term rotifer enrichments, respectively. The microalgae $\mathrm{N}$. salina is also good supplement in terms of its fatty acid profile but not comparable in growth performance to the L-carnitine and Spresso.

\section{References}


Ajith Kumar, T.T. and Balasubramanian, T. (2009): Broodstock development, spawning and larval rearing of the false clownfish, Amphiprion ocellaris in captivity using estuarine water. Cur. Sci. 97(10): 1483-1486.

Albentosa, M., Perez-Camacho, A., Labarta, U. and Fernandez-Reiriz, M.J. (1997): Evaluation of freeze-dried microalgal diets for the seed culture of Ruditapes decussatus using physiological and biochemical parameters. Aquaculture 154: 305-321.

Baker, S., Alves, D. and Bengston, D.A. (1998): Effects of rotifers and Artemia fatty acid enriched on survival, growth and population of summer flounder Paralichthys dentratus larvae. J. World. Aquacult. Soc. 29: 224-227.

Bell, J.G., Henderson, R.J., Pirie, B.J.S. and Sargent, J.R. (1985): Effect of dietary polyunsaturated fatty acid deficiencies on mortality, growth and gill structure in the turbot Scophthalmus maximus. J. Fish Biol. 26: 181-191.

Bligh, E.G. and Dyer, W.J. (1959): A rapid method of total lipid extraction and purification. Can. J. Biochem. Physiol. 37: 911-917.

Cahu, C.L., Zambonino Infante, J.L., Peres, A., Quazuguel, P. and Le Gall, M.M. (1998): Algal addition in sea Bass Dicentrarchus labrax larvae rearing: effect on digestive enzymes. Aquaculture 161: 479-489.

Castell, J.D., Bell, J.G., Tocher D.R. and Sargent, J.R. (1994): Effects of purified diets containing different combinations of arachidonic and docosahexaenoic acid on survival, growth and fatty acid composition of juvenile turbot Scophthalmus maximus. Aquaculture 128: 315-333.

Clement, P., Wurdak E. and Amsellem, J. (1983): Behavior and ultra structure of sensory organs in rotifers. Hydrobiol. 104: 89-130.

Dhaneesh K.V., Ajith Kumar, T.T., Swagat, G. and Balasubramanian, T. (2012): “Breeding and mass scale rearing of Clownfish Amphiprion percula: Feeding and rearing in brackishwater". Chin. J. Ocean. Lim., 30 (4): 528-534.

Dhert, P., Rombaut, G., Suantika, G. and Sorgeloos, P. (2001): Advancement of rotifer culture and manipulation techniques in Europe. Aquaculture 200: 129-146.

Duncan, A. (1989): Food limitation and body size in life cycle of planktonic rotifers and cladocerans. Hydrobiol. 186/187: 11-28.

Emaus, R. K. and Bieber, L.L. (1983): A biosynthetic role of carnitine in the yeast Torulopsis bovina. J. Biol. Chem. 258: 13160-13165.

Fu, Y., Hirayama, K. and Natsukari, Y. (1991): Morphological differences between two types of the rotifer Brachionus plicatilis O.F. Muller. J. Exp. Mar. Biol. Ecol. 151: 29-41.

Fyhn, H.J. and Serigstad, B. (1987): Free amino acids as energy substrate in developing eggs and larvae of the cod Gadus morhua. Mar. Biol. 96: 335-341.

Gapasin, R.S.J. and Duray, M.N. (2001): Effects of DHA-enriched live food on growth, survival and incidence of opercular deformities in milkfish (Chanos chanos). Aquaculture 193: 4963.

Hagiwara, A., Gallardo, W. G., Assavaaree, M., Kotani, T. and Araujo, A.B. (2001): Live food production in Japan: recent progress and future aspects. Aquaculture 200: 111-127.

Kissil, G. and Koven, W. (1990): Preparation of oils enhanced in highly unsaturated fatty acids (HUFA) content by low temperature crystallization separation for rotifer (Brachionus plicatilis) enrichment. Aquaculture 88: 69-74.

Lubzens, E., Minkoff, G. and Maron, S. (1985): Salinity dependence of sexual and asexual 
reproduction in the rotifer Brachionus plicatilis. Mar. Biol. 85: 123-126.

Oie, G. and Olsen, Y. (1997): Protein and lipids content of the rotifers Brachionus plicatilis during variable growth and feeding condition. Hydrobiol. 358: 251-258.

Olsen, Y., Reitan, K.I. and Vadstein, O. (1993): Dependence of temperature on loss rates of rotifers lipids and $\Sigma_{3}$ fatty acids in starved Brachionus plicatilis cultures. Hydrobiol., 255/256: 134-155.

Parra, G., Ronnestad, I. and Yufera, M. (1999):. Energy metabolism in eggs and larvae of the Senegal sole. J. Fish Biol. 55: 205-214.

Rico-Martınez, R. and Dodson, S.I. (1992): Culture of rotifers Brachionus sp. Pallas. Aquaculture 105: 191-199.

Ronnestad, I., Koven, W., Tandler, A., Harel M. and Fyhn, H.J. (1998):. Utilisation of yolk fuels in developing eggs and larvae of European sea bass (Dicentrarchus labrax). Aquaculture 162: 157-170.

Santulli, A., Puccia, E. and D'Amelio, V. (1990): Preliminary study on the effect of short-term carnitine treatment on nucleic acids and protein metabolism in sea bass (Dicentrarchus labrax L.) fry. Aquaculture 87: 85-89.

Sargent, J.R., McEvoy, L.A. and Bell, J.G. (1997): Requirements, presentation and sources of polyunsaturated fatty acids in marine fish larval feeds. Aquaculture 155: 85-101.

Sivaloganathan, B., Walford, J. and Lam, T.J. (1998):. Free amino acids and energy metabolism in eggs and larvae of seabass, Lates calcarifer. Mar. Biol. 131: 695-702.

Southgate, P.C. and Kavanagh, K. (1999): The effect of dietary n-3 highly unsaturated fatty acids on growth, survival and biochemical composition of coral reef demersal fish, Acanthochromis polycanthus. Aquat. Living Resour. 12: 31-36.

Thrush, M., Navas, J. M., Ramos, J., Bromage, N., Carrillo, M. and Zanuy, S. (1993): The effect of artificial diets on lipid and total fatty acid composition of cultured sea bass (Dicentrarchus labrax) eggs. Actas v congresso. Nac. Acuicult. pp. 37-42.

Watanabe, T., Kitajima, C. and Fujita, S. (1983): Nutritional value of live organisms used in Japan for mass propagation of fish: a review. Aquaculture 34, 115-143.

Yoshimatsu, T., Imoto, H., Hayashi, M., Toda, K. and Yoshimura, K. (1997): Preliminary results in improving essential fatty acids enrichment of rotifer culture in high density. Hydrobiol. 358: $153-157$.

Zar, J. H., 1999. Biostatistical Analysis. pp 1-662. Prentice-Hall, Illinois, USA. 1-662.

Zhang, D.M., Huang, Q., Zhou, J.X. and Wu, L.F. (2002): Effects of L-carnitine on growth performance and muscle composition of Cyprinus carpio (L.) fed diets with different levels of protein. J. Jilin Agric. Univ. 24: 82- 87. 